\title{
PSICOPATOLOGIA DA DESPERSONALIZAÇÃO
}

\author{
DARCY M. UCHôA *
}

A despersonalização foi descrita por Krishaber, em 1873, dentro do quadro da "névropathie cérébro-cardiaque". O têrmo foi usado em psicopatologia primeiramente por Dugas 17 que, em vários trabalhos, estudou o assunto e, em um dêles, em colaboração com Moutier ${ }^{18}$, criticou a teoria da "perversão sensorial" ou "teoria sensualista" defendida por Taine, Krishaber e Ribot. Este último ${ }^{55}$, todavia, afirmou que, desde 1883 já admitia a importância da cenestesia nas alterações da personalidade, verificando ulteriormente a importância primordial da sensibilidade afetiva nas transformações bruscas da individualidade. Dugas e Moutier demonstraram não haver perturbação apreciável e, muito menos, específica, das sensações, estando em jôgo o problema da consciência compreendida não como percepção pura e simples, mas como a síntese pessoal ou a relação que se estabelece entre as sensações experimentadas e a pessoa que as experimenta. Foerster (cit. por Ajuriaguerra e Hecaen ${ }^{2}$ ) descreveu, em 1903, um caso em que havia idéias de negação acompanhadas de sentimentos de estranheza em relação ao mundo exterior e certos fenômenos fóbicos. Admitindo que em tôda sensação há dois elementos, um sensorial especifico, outro em relação com as sensações orgânicas concomitantes de origem muscular, Foerster explicou a despersonalização pela não entrada na consciência dos "elementos miógenos" da sensação; haveria uma supressão da função da somatopsique, segundo a terminologia de Wernicke.

No primeiro caso publicado por Deny e Camus $16 \mathrm{~b}$ havia igualmente idéias de negação de órgãos do corpo que foram atribuídas a uma insuficiência funcional, por inibição dos "centros corticais cenestésicos", dificultando ou impossibilitando a evocação ou representação, por parte do paciente, de partes ou mesmo da totalidade do próprio corpo. E o conceito de "cenestesia cortical" (consciência do corpo), traduzindo tais casos de negação ou despersonalização a perda dela, isto é, "acenestesiopatia", com possibilidades da diminuição, aumento ou falsificação (hipo, hiper, paracenestesiopatia).

Dupré e Camus ${ }^{19}$ descreveram as "cenestopatias" como sensacões mais ou menos estranhas sentidas em partes ou na totalidade do corpo sem causas orgânicas precisas. A noção de cenestesia fol criticada por Bonnier como teórica e abstrata,

Excerto da tese apresentada à Fac. Med. da Univ. do Brasil por ocasiāo do concurso para provimento da Cadeira de Clínica Psiquiátrica. * Docente de Clínica Psiquiátrica na Fac. Med. da Univ, de São Paulo e ra Fac. Med. da Univ. do Brasil. 
incapaz de explicar satisfatơriamente os casos de despersonalizaçāo, os estados de negação e transformação corporal. Mostrou Bonnier a importância do "sentido do espaço", concretizando-se na noção do "esquema corporal" (Bonnier, schilder), "imagem corporal" (Lhermitte), "modêlo postural" (Head); segundo Bonnier, fica perturbada a função de "figuration topographique de nôtre corporalité" (cit. por Lhermitte ${ }^{47}$ ), alterando-se a orientação psiquica (auto, sômato e alopsiquica). Schilder nega que a cenestesia exerça papel decisivo na construção do ego corpora!, tendo significação as sensações provenientes do interior do nosso corpo sômente depois que entram em conexão com a imagem corporal. O esquema corporal é algo dinâmico que se desenvolve; em sua construcão, além das sensaçôes táteis, musculares, artrocinéticas, vestibulares e visuais, exercem papel de grande importāncia, segundo Schilder, a dor e o domínio motor sôbre os membros. Head e Holmes conceberam o esquema corporal como integração de tôdas as sensações, construindo-se continuamente, alterando-se por novas atividades e estímulos, podendo ser visual, tátil, mas sobretudo postural. Head insistia sôbre o caráter postural dêsse modêlo, suscetível de modificações, mas sendo continuamente usado como referência no sentido de que novas sensações, atitudes e movimentos são capazes de entrar em relaçāo com a posição do corpo em sua totalidade se.

A Neurologia estuda importantes alterações do esquema corporal numa faixa que já tem muito de comum com o plano da Psicopatologia e Psiquiatria (membros fantasmas dos amputados, anosognosia, autotopoagnosia, agnosia digital, autoscopia positiva e negativa, etc.), sôbre que nāo nos podemos deter no presente trabalho. A perda da imagem corporal e conservação dos mecanismos automáticos é denominada por Lhermitte "assomatognosia total", definindo-se a "hemiassomatognosia" pelo desaparecimento da metade da imagem corporal ${ }^{47}$. Schilder ${ }^{60}$ observou intensas alteraçōes psicológicas nesses casos, especialmente na esfera afetiva, encontrando semelhancas com o que se passa na repressão histérica, excluindo o paciente do campo consciente aquela parte do corpo que nāo mais lhe dá satisfaçāo e concluiu formulando o conceito de "repressão orgânica". Henri Ey concebe a despersonalização, os delírios hipocondríacos, a sindrome de cotard e, em geral, os transtornos de personalidade, como dissoluçóes uniformes, generalizadas, apicais, objeto assim da Psiquiatria, ao contrário das dissoluçōes circunscritas, basais, objeto de estudo por parte da Neurologia. segundo o conceito neojacksoniano que vem desenvolvendo a partir de seu importante trabalho em colaboraça com Rouart ${ }^{22}$. Essa tendência "neurologizante" da Psiquiatria cede cada vez mais lugar a concepcōes mais amplas, em que a análise estrutural e uma concepcão mais totalitária e dinâmica da Psiquiatria vão se impondo com grande fôrça ${ }^{63}$, concepçōes que sāo chamadas a contribuir para o esclarecimento de muitas incógnitas que põe, ainda hoje, o problema da despersonalizacão.

Em notável monografia Schilder ${ }^{60 a}$ definiu a despersonalização como "um estado no qual o individuo se sente completamente transformado em relação ao seu estado anterior. Esta modificação atinge o eu e o mundo exterior e o indivíduo não se reconhece como personalidade. Seus atos the aparecem como automáticos. Êle observa seus atos e comportamento, do ponto de vista de um espectador. O mundo exterior lhe aparece como novo e estranho, tendo perdido o caráter de realidade. Não há alteração do eu central, do eu em seu verdadeiro sentido (I, no sentido de W. James ${ }^{41}$ ), mas do (eu) mesmo (selbst) e a personalidade, e o eu central percebe tal modificação". Três ordens de fatos transparecem nessa definição e caracterizam a sintomatologia: sentimento de transformação do corpo (ego corporal) e da personalidade (ego psíquico), estranheza diante do mundo exterior e tendência à auto-observação $\mathrm{e}$ à auto-análise. $\mathrm{O}$ sentimento de 
transformação corporal pode ser geral ou parcial, neste último caso tal ou qual órgāo ou parte do corpo surgindo como algo diferente, estranho. Não raro o paciente sente que suas mãos, cabeça, olhos ou outra parte do seu corpo não mais the pertencem; pode tocar a parte atingida, vê-la, mas não a reconhece como lhe pertencendo. $\hat{E}$ comum a queixa de que o paciente não é mais êle mesmo, observando e analisando seus atos e comportamento como se de outra pessoa se tratasse; fica alheio, distante das pessoas e coisas, tudo the é indiferente, não participa na vida que se desenrola ao seu derredor. Outros pacientes têm a sensação de que vão perder sua personalidade, como se fôssem escapando da realidade imediata, situação que, de regra, produz ansiedade e, por vêzes, terror e pânico. Com freqüência, a despersonalização está associada à desrealização, pôsto alguns autores refiram o aparecimento isolado de um ou de outro tipo de sintomas. A autoanálise é sintoma tão freqüente que certos autores (Follin ${ }^{28}$ ) perguntam se não goza ela papel causal na despersonalização, não sendo apenas sintoma concomitante ou derivado de perturbaçāo geradora mais profunda. Krapf acentua a importância da irrealidade e da "não familiaridade", bem como as alterações do eu perceptor ${ }^{45}$. Usando a terminologia de Wernicke, descreve Krapf a despersonalização somatopsiquica (despersonalização do corpo) e a alopsiquica (desrealização, de Mapother e Mayer-Gross), opondo essa despersonalização de todo o mundo da percepção (corpo e mundo ambiente) à "desanimação" como perturbação característica do eu perceptor, atingido como sujeito. K. Haug ${ }^{34}$ também diferencia a despersonalização em auto, sômato e alopsiquica, segundo é atingido o eu psíquico ou o corporal ou o mundo ambiente, acentuando a necessidade da perturbação da consciência, bem como da energia vital e psíquica (impulsos, atividade, afetividade). A despersonalização surge, segundo Haug, quando há perturbação das conexões vitais ("bei Störung des vitalen Zusammenhangs"). Vamberto de Morais acentuou o caráter de "sindrome subjetiva"; o despersonalizado comunica seus sintomas e os sente como mórbidos ${ }^{65}$. São conhecidos os trabalhos de Shorvon e col. ${ }^{58,59}$ em que a despersonalização é interpretada dentro dos conceitos de inibição e excitação da escola de Pavlov, sendo considerada como um fenômeno inibitório cortical. Segundo Janet ${ }^{42}$, tem o despersonalizado a sensação de algo incompleto (sentiment d'incomplétude), de inacabado, fazendo a despersonalização parte do amplo quadro da "psicastenia".

A maioria dos autores admite que a despersonalização não é quadro específico, podendo surgir em quase todos os quadros da nosologia mental, principalmente nos estados toxinfecciosos, nas esquizofrenias e timopatias. Segundo Shorvon ${ }^{58}, 88 \%$ dos despersonalizados são de tipo compulsivo, fato já assinalado por Reik ${ }^{54}$. A despersonalização tende a surgir em personalidades diferenciadas, com vida interior mais ou menos rica, personalidades tendendo à introspecção e à fuga dos problemas do meio exterior. Não è rara a concomitância com as elocubraçōes obsidente-compulsivas referentes a problemas metafísicos-filosóficos sob forma de dúvidas e incertezas quanto à própria situação do existir e do viver, típicos estados de "angústia exis- 
tencial". Em trabalho anterior ${ }^{63 a}$ relatamos interessante observação a êste respeito (caso 9).

Krapf 45 procura distinguir as desrealizaçōes corticais da verdadeira despersonalização, adotando o critério da. maior ou menor aproximação do "eu". Segundo Krapf as desrealizaçōes corticais (agnosias visuais e da imagem de si mesmo) com irrealidade e infamiliaridade, são experiências "instrumentais" (o "eu" está secundàriamente implicado). Nelas pode-se incluir a desrealização hemianópsica ou hemianosognósica (Ehrenwald, von Stöckert, Krapf) e as despersonalizações por "obnubilação oniróide" ("traumhafte Benommenheit" de Storring ${ }^{61)}$. Aqui o caráter de perda da realidade está muito mais afastado do "eu" que nos verdadeiros despersonalizados. O autor resume sua idéia na seguinte frase: "O mundo dos agnósticos é infamiliar porque é irreal e o dos despersonalizados é irreal por ser infamiliar" (grifos do autor).

Do ponto de vista clínico-fenomenológico, encontramos a despersonalização como neurose em estado de maior ou menor pureza, como sintoma (predominante ou não) em quadros neuróticos (ansioso-compulsivos principalmente) e psicóticos (sobretudo esquizofrênicos e melancólicos). Nāo se caracteriza a despersonalização pela morfologia clínico-nosográfica, mas encerra sentido de proteção ou defesa na psicodinâmica geral da personalidade, traduzindo "doença do ego" (Federn ${ }^{24}$ ), mas também esforços de cura espontânea, não raro a ela se seguindo os processos de "restituição" (Freud) sob forma de projeçōes alucinatório-delirantes. Pode tal defesa ser eficiente e então o quadro estacionar, a despersonalização tendo aspecto mais ou menos puro ou colorindo a sintomatologia neurótica. Se o processo defensivo é ineficiente no deter o processo desintegrativo, então poderá se entrosar com a fenomenologia psicótica geral, surgindo em francos estados esquizofrênicos e melancólicos sobretudo. Disso resulta a posição sui generis que a despersonalização ocupa em psicopatologia, tema que vem sendo estudado por neurologistas, psiquiatras, psicólogos e mesmo filósofos. A investigação psicanalitica muito tem contribuido para o esclarecimento de tão fascinante tema ao procurar apreender os mecanismos básicos, inconscientes, fundamentalmente responsảveis pela exteriorização da despersonalização em estado puro ou colorindo a fenomenologia neurótica ou psicótica.

Em sua carta a Romain Rolland, Freud ${ }^{29 a}$ aproximou-se do problema da despersonalização e da estranheza (Entfremdungsgefühl), considerando ambos como mecanismos de defesa, a despersonalização podendo iniciar o caminho para uma cisão completa da personalidade. Segundo Nunberg ${ }^{51}$ os estados de personalização dependem de um desligamento da libido dos objetos do mundo e conseqüente investimento (aumento de carga) do ego. A perda da libido é sentida como trauma narcísico, sentindo-se o ego incapaz de satisfazer os impulsos libidinosos. Os objetos inconscientes são afetados, fantasias inconscientes penetram na zona consciente mercê da fraqueza do ego. Reik ${ }^{54}$ assinala o masoquismo inconsciente, a autopunição (muitas vêzes na auto-observação compulsiva), o forte sadismo contra os 
objetos revertido, não raramente, contra os próprios pacientes. Tal sadismo guarda relação com a auto-observação compulsiva que substitui os afetos reprimidos, mas já é indicio de cura espontânea. Reik considerava a despersonalização como mecanismo de defesa contra uma parte da realidade ou contra os impulsos reprimidos. Schilder $60 \mathrm{~b}$ dá grande importância à auto-observação, às tentativas falhadas de fuga do mundo exterior, retirando o paciente parcialmente dêle sua libido; há conservação parcial das cargas do ego (perceptor) $€$ do superego, pois não há destruição (apenas estranheza) do mundo e uma parte da personalidade (o superego) observa a outra. Mais recentemente Schilder ${ }^{60 d}$ acentua o papel do exibicionismo, escoptofilia e tendências uretrais, assinalando que a heterossexualidade está perturbada pela irrupção de vários tipos de sexualidade primitiva combinada com impulsos sadomasoquísticos. Sadger ${ }^{j i}$ valorizou os impulsos exibicionistas e escoptofilicos, a angústia de castração com sentimentos de culpa, os impulsos de masturbação psíquica, a perda precoce de um dos pais durante a primeira eflorescência sexual.

Oberndorf, em vários trabalhos ${ }^{52}$, vem estudando detidamente o problema da despersonalização, tendo postulado a teoria da erotização do pensamento, da identificação com o genitor do sexo oposto quanto "ao pensamento", bem como o importante papel desempenhado pela defesa contra a angústia. A identificação com o pensamento do genitor do sexo oposto incorpora-se ao superego, dando ao tipo de pensamento da criança um modêlo do sexo do pai pensador. Em trabalho mais recente afirma Oberndorf 52d ser a despersonalização defesa contra a angústia. Segundo Federn ${ }^{24}$, a desrealização consiste em perturbação da periferia do ego em relação a uma carga de sentimento que deve ser distinguida da carga de objetos. O sentimento de ego periférico não é, de forma alguma, idêntico ao sentimento do tato e outras funçōes sensoriais. Federn procurou criar uma nova psicologia do ego, baseada nas descobertas e primeiras elaborações de Freud, mas com sensíveis diferenças e, em certos casos, francamente opostas a elas. Postula êle a existência de fronteiras para o ego corporal e para o ego mental, com cargas libidinosas; se estas são retiradas, surge a despersonalização, não como retirada da libido da representação dos objetos, mas como retirada dela dos limites do ego (ego-boundaries). Assim, partes do corpo ou êste em sua totalidade, como tôda a vida psíquica em seus vários aspectos (pensamentos, afetividade, vontade, etc.) podem ser despersonalizados, quando há redução ou perda da carga libidinosa (narcísica) dos limites do ego corporal e psíquico. Assim a despersonalização é um processo defensivo encontradiço no início de neuroses e psicoses (Federn, Schilder), que desaparece quando tais estados psicopatológicos estão plenamente desenvolvidos (Federn), podendo também surgir no declínio dêles (Schilder). Outros autores (Hesnard ${ }^{38}$, Tausk ${ }^{62}$, Fenichel ${ }^{26}$, Feigenbaum ${ }^{25}$, Wittels ${ }^{64}$, Eidelber ${ }^{20}$, Hartmann ${ }^{33}$, Bergler ${ }^{4}$, Bockner ${ }^{8}$, Peto ${ }^{53}$, Ferenczi ${ }^{27}$ ) têm trazido importantes contribuições ao problema da despersonalização, destacando-se, todavia, as fundamentais formulaçōes da escola psicanalítica inglêsa (M. Klein ${ }^{43}$, H. Rosenfeld ${ }^{56}$ ), sobretudo no referente ao "splitting" dos im- 
pulsos, dos objetos e do próprio ego e ao mecanismo da "identificação projetiva" característico dos estados desintegrativos esquizoparanóides. Tais conceitos completam as formulaçōes sobretudo de Schilder ${ }^{60}$, Nunberg ${ }^{51}$, Sadger ${ }^{57}$, Oberndorf ${ }^{52}$, Federn ${ }^{24}$, ao investigar o comportamento dos impulsos agressivos no quadro da despersonalização. Surge uma concepção psicodinâmica mais ampla, mais capaz de explicar o estado psicopatológico da despersonalização e a desrealização como neurose ou permeando a sintomatologia hipocondríaco-delirante (delirios hipocondríacos, somáticos, síndrome de Cotard) em outros de mais avançada regressão dos impulsos e do ego para fases as mais recuadas do desenvolvimento da personalidade. Se a unidade do ego é cada vez mais ameaçada, aos fenômenos de despersonalização podem se suceder os demais indícios de sua dissolução. Eis o quadro da despersonalização neurótica e despersonalização psicótica com características clínico-nosográficas diversas, mas ambas traduzindo tentativas de proteção da personalidade, defesas do ego (e superego) ou formações de compromisso (sintomas) em face de intoleráveis ansiedades fundamentalmente radicadas aos níveis biológico-institivos mais profundos da personalidade.

\section{OBSERVAÇOES}

Caso 1 - L. C., branco, casado, brasileiro, 20 anos, examinado em 20-6-1948. Desde 4 anos passados vem sentindo "estranheza" em relação a pessoas, objetos e situaçóes. Quando é atacado pelo "esquisitismo", o mundo fica estranho, lugares e situações familiares "ficam diferentes". Tem de fazer esfôrço para reconquistar o sentimento de familiaridade, para sentir as coisas e pessoas como dantes. Quando tal sensação aumenta, tem a impressão de que "já não sou eu mesmo" quem está ali, observando, conversando ou agindo, tudo ficando "automático", como se "eu não mais tomasse parte na vida". Com frequiencia, sente que "a vida, as coisas, as pessoas văo sumindo, desaparecendo"; então teme que êle próprio também desapareça. Desenvolveu-se "agorafobia" em relação com o receio de ser invadido pelo "esquisitismo". Há 8 anos passados teve "confusão de idéias", com mêdo de perder a memória, o que foi julgado pelo médico assistente como efeito de masturbação. Informa que seu pai é muito nervoso e irritadiço. O casal teve sete fllhos (uma irmã faleceu aos 8 anos de idade). Vem consultando muitos médicos, disse-nos, sem qualquer resultado. Acentuou-se o "mêdo de ficar louco", concluindo os médicos ùltimamente tratar-se de "nervoso" (vários exames de laboratório como complemento aos exames clínicos tendo sido negativos). Por fim fol aconselhado o tratamento psicanalitico.

Conclusões do tratamento $e$ investigação psicanalíticos (390 horas): 1) identificação feminina como defesa contra a ansiedade de castração; 2) regressão da líbido para a fase oral-receptiva, sentindo-se extraordinàriamente dependente de sua mãe e de sua espôsa; 3) estreitas relações entre tais constelacoóes afetivas e o forte sadismo oral para a genitora; 4) a despersonalização surgia quando se incrementava o conflito entre a feminilidade e as tentativas de afirmaçăo viril; 5) a identificação com genitor do sexo oposto e sua defesa contra ela, assim coma a acentuação dos impulsos escoptofilicos e exibicionistas, tiveram papel importante na sintomatologia; 6) o mecanismo masoquístico de defesa do eu contra a acentuada agressividade oral para os objetos primários (máe particularmente) foi decisivo no provocar a desrealização e despersonalização, repetindo-se tal situação nas relações de transferência; 7) a despersonalizaçāo traduz aqui mecanismo de defesa do eu contra situaçôes perigosas nos vários niveis de estratificação mental, 
desde a ansiedade de castração forçando uma situação edipiana invertida até os mais recuados niveis de ambivalência oral; 8) a seleção da neurose (despersonalízação) traduz, a nosso ver, fraqueza de carga do eu, que recorreu a um mecanismo autodestrutivo de tipo masoquístico para evitar uma aniquilação total. A defesa atinge aqui o próprio eu, alterando-lhe os limites, diminuindo (pôsto que não acentuadamente) sua diferenciação do mundo exterior.

Caso 2 - R. L., casada, 26 anos, examinada em maio de 1951. Há 4 anos teve a primeira crise de "estranheza", que se repetiu pouco antes do seu casamento (há 8 meses). Há 2 meses tal estado tornou-se quase permanente, sendothe dificil precisar os momentos em que "via as coisas claramente, como elas são realmente". Tal estranheza fixou-se com mais intensidade sôbre a "noção de sua pessoa", ficando em dúvida se "é ela mesma ou outra pessoa", achando-se esquisita, diferente quanto à sua pessoa e quanto ao seu corpo (estavam afetados o ego corporal e o psíquico). Tem sensação de "ôco" ou "vazio" por dentro, com impressão de que já não é ela mesma, sentindo que tudo ao seu derredor é diferente, estranho, esquisito. Reconhece as pessoas, mas é como "se não sentisse a presença delas, como se mais nada significassem". Estranha seu próprio corpo tomado em sua totalidade (não apresentou jamais fenômenos parcials de despersonalizaçāo). Acha-o esquisito, val ao espêlho, olha-se, analisa-se, sente "indiferença com forte sensação de que estivesse a examinar e observar outra pessoa" (sic). Quase sempre tais fenômenos são acompanhados de sonolência, "como se quisesse dormir para fugir de alguma situação dificil". E prêsa, então, de sensação de passividade e de indiferença. $E$ assim se expressa: "tudo me é indiferente, nada faço, não vivo, sou vivida, as coisas acontecem, eu nada tenho que ver com elas". Diz que tal estado sobrevém quando está tranqüila, quando já venceu uma "crise de ódio". O sentimento de passividade entrosa-se, não raramente, com o de imobilidade: "sinto-me parada, imóvel como um désses postes de luz elétrica da rua; é como se também o tempo tivesse parado, nada acontece nem acontecerá, eu saí da vida". Ausência de antecedentes neuropsicopáticos familiares.

Conclusôes da investigação psicanalitica (290 horas): 1) intenso sentimento de inferioridade física aparentemente entretido por hipertricose facial não acentuada; 2) identificação masculina (com o pai e o irmão primogênito) como fuga da "mãe má" e como tentativa de soluçāo dos conflitos edipianos; 3 ) necessidade de negar o "complexo masculino", afirmando sua feminilidade (concepção, negação de sinais físicos sugestivos de masculinidade); 4) tal conflito agravava-se sempre em face das atitudes agressivas por parte de sua mãe, sendo que o ódio a esta, quando eficientemente reprimido, era seguido por estado de tranqüilidade, quietude e despersonalizaçāo; 5) a identificação com o genitor do sexo oposto (principalmente no setor intelectual e profissional) e a necessidade de sua repressão para a afirmacão do próprio sexo, tiveram papel importante; 6) a despersonalização traduz aqui defesa contra o se sentir feta, disforme, com hipertricose, contra a impossibilidade de negar sua "masculinidade"; nega seu corpo, sua pessoa, os tracos físi$\cos$ e psiquicos de identificação masculina e, sobretudo, nega o sadismo contra sua mãe; 7) todo um conjunto de situações perigosas consubstancia-se numa angústia básica cuja essência é o mêdo de represália, de rejeição e abandono por parte de sua māe. A paciente defende-se dos impulsos agressivos revertidos contra si mesma, usando mecanismo masoquístico, de submissão ao superego, mercē do qual são atingidos os limites do ego, diminuindo sua diferenciação do mundo externo.

Caso 3 - M. M., brasileira, solteira, 28 anos, professôra, examinada em outubro de 1946. Informa que, desde 6 anos passados, vem se sentindo muito "nervosa", com frequientes sensações de que "vai sumindo, desaparecendo", o mundo e as coisas ao seu derredor ficando "encobertas, veladas, diferentes". Acompanha-se tal sensação de perturbações visuais, como se visse "pontinhos luminosos" nas pessoas e objetos. Trata-se, diz a paciente, "de algo indefinido, esquisito, dificil de pre- 
cisar". Repetidos exames oftalmológicos têm sido negativos, aconselhando ùltimamente os clinicos que tratasse do "nervosismo". Sente que é algo mais intimo, mais perto de si mesma, não é nos olhos, pōsto se reflita em grande parte nêles. Quando tem a sensação de que vai sumindo ou desaparecendo, tem angústia, palpitações, mas explica que, "embora tudo venha misturado com mẽdo, não é mêdo só". Em tais estados tem a impressão de não ouvir sua própria voz quando fala ou, entāo, a escuta distante, como vindo de longe ou de outras pessoas. Tem, com freqüência, "aflição no estômago", com impressão de que tal órgăo desapareceu ou esteja deformado, diferente. cltimamente vem sentindo que não tem braços e antebraços como se tivessem desaparecido. Apalpa-os compulsivamente, reconhece que se enganou, mas não os sente como the pertencendo, ficando perplexa e ansiosa quando isso acontece. Contava 13 anos de idade quando tão insólitos sintomas apareceram pela primeira vez. A sensação de ir sumindo, desaparecendo, coincidiu com a menarca. A mãe tranqüilizou-a, dizendo estar nervosa pelo aparecimento do fluxo catamenial e que o "nervosismo" dependia disso. Todavia, sempre teve ciclos menstruais normais, acostumou-se com éles, mas o "nervosismo" persistia acompanhado das sensações de estranheza e dos demais sintomas de despersonalização. Houve certa atenuaçāo e logo, desaparecimento, para reaparecerem aos 22 anos e persistirem até o presente momento. Explica que o mêdo de sair sozinha, de estar na rua desacompanhada depende tão só de tal sintomatologia, isto é, do mêdo de perder sua personalidade, tenfo de fazer grandes esforcos para que isso não aconteça. O exame somático com inúmeras provas complementares foi negativo. Acabava de extrair todos os dentes, pois as radiografias revelaram focos infecciosos, sem qualquer resultado benéfico.

Conclusões do tratamento $e$ investigaçio psicanalitica (410 horas): 1) experiências múltiplas de sedução sexual na segunda infância de natureza traumática reativaram a situação edjpiana e a ansiedade de castração; 2) o conflito intenso de ambivalēncia com sua mãe foi agravado pelo novo matrimônio desta última quando a paciente contava 8 anos de idade; 3) mais superficialmente a paciente odiava mãe e padrasto; em camada mais profunda sofria pela frustração por parte de sua māe quando a preteriu em favor de seu pai, do irmão primogênito e, por fim, do padrasto; 4) sob a camada de ódio pelas seduçōes do padrasto, que reativaram a ansiedade de castração, a análise revelou novos investimentos libidinosos de tipo edipiano com conflitos de culpa e médo de autodestruiçāo; 5) a paciente apresentava intensa fixação oral-receptiva a sua mãe, o amor com extrema dependência revelando-se defesa contra o intenso sadismo oral; 6) a perda dos limites do eu (despersonalização) traduzia mecanismo defensivo contra essas múltiplas situaçōes de perigo. A angústia básica dependia do mêdo do auto-aniquilamento pela reversão dos impulsos contra o próprio eu, tal mecanismo masoquístico sendo a causa mais profunda da sintomatologia.

Nos 3 casos citados a despersonalizaçāo representava uma defesa mais forte, enérgica e autodestrutiva, do ego em face de impulsos demasiado perigosos e ameaçadores. Para evitar a autodestruição total, o ego alienava partes de si mesmo, sentindo-se os pacientes diferentes, apreendendo diversa e deformadamente os objetos e situações do mundo. O resultado terapêutico comprovou tais formulações e conclusões, havendo desaparecimento da sintomatologia com a compreensão e análise sistemática e consistente dos problemas envolvidos. A despersonalização, à luz dêsses 3 casos, pode ser considerada como formação de compromisso ou formação de sintomas, mas significa também defesa ante situações perigosas, em que a agressividade infantil, intensa porém insuficientemente reprimida, é manipulada em têrmos de projeção defensiva e revertida sôbre o próprio ego 
com ameaças de seu aniquilamento ou destruição total. A cisão parcial atua como imunizante, evitando, quando ainda possível, o completo despedaçamento do ego, como soi ocorrer nos quadros esquizofrênicos avançados.

Entre os pacientes internados nos Hospitais Psiquiảtricos Franco da Rocha e Pinel, cujas observaçōes estão expostas com minúcias na Tese citada, estudamos 12 casos de despersonalização em psicóticos que classificamos em três grupos principais: despersonalização com cisão mais ou menos completa da personalidade ( $\operatorname{casos} 4,9,10,13$ ), despersonalização associada a fenômenos de automatismo mental e projeção alucinatório-delirante (casos $5,7,12,15)$ e casos com fenômenos hipocondríacos e de negação delirante (casos $6,8,11,14)$. O estudo minucioso revelou a existência de conflitos intrapsíquicos intensos num ego atônico, de fraca carga narcísica, com tendência a reagir diante de situações de angústia ou traumas emocionais intensos usando o "split". Se tal defesa se detém, surge o quadro da despersonalização neurótica; se ela se mostra insuficiente, a regressão prossegue para os níveis mais profundos da personalidade, para a fase do "narcisismo primário" (Freud) ou melhor, para aquela em que nāo há ainda coesão dos núcleos do ego em organização única. Surge, então, o quadro esquizofrênico que, em sua forma avançada, se revela como fragmentação do ego em núcleos (secundários) de organização somatopsíquica funcionando algo automàticamente, regidos pelo principio do prazer, longe da realidade, incrustados profundamente na personalidade rôta, sem continuidade psiquica. Muitos investigadores chamaram a atenção para os estađos de perplexidade (Störring ${ }^{61}$ ) e de angústia (Gruhle ${ }^{31}$, principalmente) nas fases iniciais do "processo" esquizofrênico. Tais afetos já estão a traduzir a sensação de perigo, de ameaça próxima. A retirada de libido dos objetos do mundo (Freud) já é medida de defesa que dá início ao processo regressivo. Neste a despersonalização é um marco muito importante a traduzir esfôrço desesperado de autoproteção para que seja evitado o extremo perigo do esfacelamento do ego que aliena partes de si. mesmo para não sucumbir nos fenômenos gerais de desintegração da personalidade. Dai as estreitas relações, assinaladas por vários autores, entre a despersonalização e a esquizofrenia; a nosso ver, a despersonalização já deve ser considerada como mecanismo esquizóide visando evitar a catástrofe esquizofrênica. Em nossos casos verificamos que, quando o mecanismo despersonalizante não consegue deter a marcha progressiva do processo psicótico, inicia êle tôda uma sintomatologia psicótica de tipo restituidor (alucinações, delírio, fantasias de reconstrução do mundo, certos fenômenos catatônicos).

A estranheza e negação de órgãos estão estreitamente ligadas aos fenômenos hipocondríacos (casos $6,8,11,14$ e 15), surgindo muitas vêzes, como contra-cargas a fim de anular as sensações desprazerosas por aumento de carga libidinosa dos órgãos envolvidos (Tausk ${ }^{62}$ ). Tal aumento de carga faz parte dos fenômenos regressivos que sucedem ao abandono dos objetos. Tal defesa tem certa analogia com a repressão histérica e com a "repressão orgânica" (Schilder ${ }^{60}$ ). O ego procura defender-se das sensa- 
çōes desagradáveis emanando de tal ou qual órgão (do ego corporal), deformando-o ou alienando-o. A relação do paciente com tais órgãos revela o conflito: de um lado desinteressa-se do mundo exterior para fixar seu interêsse na observação dos órgãos, e de outro, sofre por tais sensações de desprazer. Alguns autores assinalam as tendências agressivas do hipocondriaco para os objetos familiares de que se pune com o sofrimento (Heiman ${ }^{35}$ ). A estranheza aqui é defesa organizada a niveis menos arcaicos, quando permanece dentro dos limites neuróticos (hipocondria e despersonalização neuróticas), mas pode se mostrar ineficiente e o processo patogênico avançar para o quadro da hipocondria delirante ou para os delírios de negação, tipo Cotard. Os revestimentos libidinosos por regressão atingem os núcleos corporais do ego, as correspondentes contra-cargas defensivas dando a sintomatologia deformadora e alienadora de órgãos e aparelhos (casos 6, 8, 11, 14). Assim orientamo-nos no sentido de uma compreensão genéticodinâmica da despersonalização: traduz ela conflitos muito intensos e não solucionados dentro da personalidade somatopsíquica de um lado, e de outro, aponta um dinâmico significado de defesa contra situações que pōem em perigo o próprio ego. O conceito genético ressalta de sua origem remota, isto é, nos conflitos infantis: intensos ou repetidos traumas traduzindo situação de frustração crônica para a criança em desenvolvimento provocam mais ou menos acentuados "splits" dentro do ego (Ferenczi 27b), que tenderá a usar largamente tal "cisão" ante conflitos atuais dificilmente superáveis de outra forma. Freud disse, certa vez, que o ego poderia atenuar muito seu trabalho de repressão defensiva, deformanđo-se, criando traços caracterológicos anormais. Também na despersonalização a defesa se processa não por expulsão de conteúdos inaceitáveis do id (pelo egosuperego), mas se realiza dentro das próprias fronteiras do ego, em seus limites mais periféricos ou em sua estrutura mais central. É uma fuga de situaçōes angustiosas (Oberndorf ${ }^{52}$ ) mediante um método autodestrutivo, de auto-eliminação mesmo, para ser evitada a autodestruição total. Não raro, temos a impressão de que, a essa luz, a defesa é mais nociva do que a situação perigosa, mas esta se configura não tanto em função da objetividade do trauma atual, mas principalmente ante tôda uma continuidade de situaçōes internas de alto sentido traumático.

A cisão do ego (Spaltung, split) foi assinalada por Bleuler ${ }^{3}$ ao estudar a demência precoce (tipo Morel-Kraepelin) com o nome de esquizofrenia, sendo considerada por muitos autores um dos mais especificos mecanismos esquizóides de defesa. Freud ${ }^{20 b}$ e c aproximou-se do estudo da cisão do ego no processo defensivo estudando o fetichismo, sendo considerado o fetiche um substituto para a percepção da falta do órgão genital masculino na mulher, negando assim a angustiosa sensação de castração. Em uma série de trabalhos, Fairbairn ${ }^{23}$ afirma ser a posição esquizóide a situação básica originária no desenvolvimento ulterior do ego, o estado de "split" do ego primitivo explicando a maior freqüência e amplitude dos estados psicopatológicos considerados esquizóides (esquizofrenia prơpriamente, personalidade 
psicopática de tipo esquizóide, caráter esquizóide, estado esquizóide ou episódio esquizóide transitório incluindo uma grande proporção de casos de "nervous breakdown"). Frisa o mesmo autor as relaçōes entre a histeria e a esquizofrenia sôbre que já chamara a atenção Abraham 1a, ao estudar, em 1908, as diferenças psicossexuais entre ambas. Também H. Claude ${ }^{15}$ e sua escola mostraram as íntimas relações entre a histeria e a esquizofrenia. O mecanismo psicológico da "cisão" é encontrado, com freqüência, na dissociação histérica da personalidade (nos graus extremos surgindo os estados de personalidade múltipla ou "double conscience") e, de forma mais acentuada, nos casos de dissociaçāo ou desintegração esquizofrênica. Não pode tal mecanismo por si só explicar problema tão complexo como o da seleção da neurose ou da psicose, para o que têm contribuído a teoria dinâmica dos instintos e as novas formulaçōes sôbre o problema das relações de objeto desde o inicio da vida extra-uterina. De outro lado, a "cisão" pode ocorrer em vários níveis, guardando relação com o mecanismo da regressão (dos impulsos e do sistema ego-superego), de tão grande importância na solução neurótica ou psicótica dos conflitos intrapsíquicos. Além da "regressão", outros mecanismos de defesa - sobretudo negação, idealização, repressão - acompanham a cisão do ego. Segundo Federn ${ }^{24}$, a despersonalização traduz "falta de firmeza interior", indicando que o processo defensivo atingiu sua estrutura. A fôrça do ego depende da riqueza e consistência de sua carga narcísica (Freud, Federn). Prováveis mas ainda obscuros fatôres constitucionais devem nela tomar parte, parecendo mais satisfatória a concepção de Federn sôbre a carga de libido neutra ou média, capaz de flutuações positivas e negativas em função de fatôres vários. $O$ ego primitivo é pobremente integrado, o que explica sua predisposição às cisões mais ou menos normais e às patogênicas (posição esquizóide de Fairbairn ou esquizoparanóide de M. Klein). Seus primeiros núcleos, dependentes da fase de auto-erotismo inicial, vão logo sofrendo a influência das primeiras relaçōes com o seio materno, demais partes do corpo da mãe ou com esta de forma integral. Há uma realidade externa e outra interna no ego em desenvolvimento, a última interferindo sôbre a primeira, o que explica os vários aspectos da mente infantil. $O$ ego se firma e se consolida mais e mais à medida que vai avançando o desenvolvimento dos impulsos e mais se diferenciando os objetos (desenvolvimento das relaçōes de objeto). As sólidas identificações primárias com a mãe boa (não demasiado frustradora), compreensiva e paciente, que educa sem castigar, mas compreendendo sempre as necessidades e conflitos dêsse mundo interior dos seus filhos, auxiliam muito a formação de um ego uno, estruturado sòlidamente, capaz de resistir ao impacto das agressões do meio. A despersonalizaçāo significa que o "split" atingiu não apenas instintos e objetos, mas já a estrutura do próprio ego, afetando sua periferia na sintomatologia da estranheza do mundo (desrealização) ou sua estrutura mais central nos fenômenos de despersonalizaçāo auto e somatopsiquicos. No último caso, ao progredir o processo patogênico, vão surgindo defesas mais arcaicas: os núcleos corporais e psíquicos da personalidade são atingidos, o ego tende à desintegração, re- 
duzindo-se mais e mais a seus primitivos núcleos, surgindo os casos de hipocondria delirante, de delírios somáticos, niilistas. Na profunda regressão, dos esquizofrênicos autênticos encontramos êsses núcleos de personalidade rôta, fragmentada, funcionando quase independentemente uns dos outros, dando o aspecto de funda dissociação que caracteriza o pensamento paralógico de tais pacientes.

A despersonalização, concordamos com Federn, é doença do ego e, como tal, só poderá ser compreenđida em função dos conflitos e vicissitudes de sua gênese. A nosso ver, o conceito deve ser ampliado, desde os mais leves estados de sentimento de perda do ego com as sensaçōes de estranheza de idéias, afetos e atos, até as sensações de órgãos estranhos ou alienados, havendo nos casos extremos, cisão maior ou menor da personalidade total. O nosso material fêz-nos sentir com muita fôrça a possibilidade da "cisão" do ego nos vários níveis do seu desenvolvimento, mas a solução neurótica ou psicótica dependerá de outros mecanismos acompanhantes (regressão, negação, repressão, projeção, introjeção). A falha dos mecanismos neuróticos de defesa, ao prosseguir o processo patogênico, vai pondo em jôgo os mecanismos arcaicos psicóticos, surgindo, então, a despersonalização como psicose ou na psicose (geralmente de tipo esquizofrênico ou melancólico). Temos assim a despersonalização como neurose e na neurose (histérica ou compulsiva), como psicose e na psicose, eventualidades clinicamente diversas, mas tôdas compreensiveis em sua problemática psicopatológica dentro de um amplo conceito psicodinâmico de evoluçāo e dissoluçāo da personalidade somatopsiquica integral.

\section{CONCLUSÕES}

1 - Do ponto de vista clínico-nosográfico a despersonalização pode aparecer em estado de pureza (relativo) como neurose ou como psicose, com bem maior freqüência surgindo na neurose e na psicose.

2 - A despersonalização pode ser definida como um estado em que o paciente se sente diferente do que era anteriormente no domínio do ego corporal, do ego psíquico e quanto às relações com o mundo exterior. $\dot{E}$ aceitável a terminologia de Wernicke: despersonalização somatopsiquica, autopsiquica e alopsiquica (estranheza do mundo ou desrealização de Mapother-Mayer-Gross).

3 - A despersonalização pode atingir aspectos parciais ou a totalidade do ego corporal e psíquico: alienação ou estranheza de tal ou qual órgão ou parte do corpo ou dêste de uma forma geral, de afetos, idéias ou volições, como da totalidade do psiquismo. Em casos extremos surge o quadro do delirio das negações ou, então, o fenômeno da "double conscience" ou das personalidades múltiplas.

4 - A aproximação de casos de despersonalização, do ponto de vista etiopatogênico, com certas afecções neurológicas (alucinação dos membros 
amputados ou membros fantasma, anosognosia, autoscopia) trouxe certos esclarecimentos quanto ao mecanismo neurofisiopatológico. Mas, trata-se, aqui, como mostrou Krapf, de fenômenos instrumentais mais distantes do ego que as despersonalizações autênticas (refere-se o autor aos casos de desrealização hemianópsica ou hemianosognósica estudados por Ehrenwald, von Stöckert e Krapf). Além disso, a mera consideração de mecanismos neuro-anátomo-patológicos (no caso ainda obscuros) não poderá esclarecer a psicodinâmica complexa dos despersonalizados.

5 - Em nosso material (15 observações consignadas in extenso na tese citada) o exame clínico (com múltiplas provas complementares) foi negativo quanto à existência de afecção orgânica do sistema nervoso. Em todos os nossos pacientes (com maior evidéncia nos 4 primeiros casos), sentimos tratar-se de "doença da personalidade" ou, mais precisamente de "doença do ego". Surgiram conflitos intensos impelindo o ego ao "split". A satisfatória solução dos conflitos foi seguida de cura nos 4 primeiros casos. Como ficou referido, os 11 pacientes das observaçōes seguintes não responderam às técnicas de choque, em alguns dêles seguidas de intervenção psicocirúrgica. Tratava-se de despersonalização em quadros de psicose grave, onde nossa intenção foi sobretudo investigar problemas de psicopatologia e não tanto de terapêtica.

6 - Encontramos os seguintes mecanismos nos casos estudados: a) conflito entre tendências hétero e homossexuais interferindo intensamente no caráter e no comportamento (caso 1), sendo que a necessidade de reafirmar o próprio sexo em situações fortemente sugestivas de tendências contrárias provocava a despersonalização; b) intenso conflito no sentido da rejeição do ego físico por sentimento de inferioridade foi observado (caso 2) em paciente que se esforçava por negar seu corpo, mas logo surgiram conflitos emocionais com sua mãe. O conflito (hêtero e homossexual) guardava relação com a identificação com o pai e a rejeição do papel feminino. Ao reafirmar seu próprio sexo (feminino) por rejeição da masculinidade, surgia a despersonalização; c) em ambos os casos o aprofundamento da análise demonstrou, todavia, que o essencial estava mais profundamente radicado. Com efeito, surgiu intenso conflito entre tendências de forte dependência da mãe e múltiplas sensações de rejeição por parte dela. Caracterizou-se uma situação muito profunda de ansiedade básica em relação com o mêdo de auto-aniqüilamento (morte). Havia reversão da agressividade sôbre o próprio ego em grau tão intenso que a defesa adequada era o "split" (mecanismo masoquístico).

7 - Em muitos casos a "cisão" não é eficiente nem suficiente como defesa, mesmo processando-se nos níveís mais arcaicos por efeito da regressão, surgindo, então, os mecanismos de restituição (Freud), como projeções alucinatório-delirantes, fenômenos automáticos, de influência, configurando-se o quadro da despersonalização dentro da psicose. Esta traduz maior fraqueza do ego ou maior intensidade dos conflitos. 
8 - Em muitos casos notamos a estreita relação entre a despersonalização e a hipocondria, concebida como aumento de carga da representação dos órgãos em detrimento da carga dos objetos. A repressão por contracarga das sensações desprazerosas levava aos sentimentos de alienação ou estranheza, como mostraram Tausk, Fenichel e outros. Todavia, também nesses casos, uma investigação mais profunda revelou sempre impulsos de agressão para objetos imediatos (como revivescência dos objetos primários), revertidas contra o próprio ego. Se a hipocondria é fenômeno de aumento de carga narcísica dos órgãos (Freud), também a componente agressiva em órgãos simbolizando objetos surge, por vêzes, com muita evidência.

9 - Na despersonalização neurótica há indicação da psicoterapia analiticamente orientada (exumação dos conflitos e sua solução) ou, preferentemente, da terapêutica psicanalítica. Quando constitua parte da sintomatologia de determinada forma psicótica, a despersonalização acompanha os principios gerais da indicação das modernas terapêuticas biológicas de choque e dos modernos métodos psicoterápicos.

\section{SUMMARY}

\section{Psychopatholy of depersonalization.}

1 - From a clinical-nosographical point of view depersonalization appear in a pure state (relative), as $a$ neurosis and in the neurosis, as $a$ psychosis and in the psychosis.

2 - Depersonalization can be defined as a state in which the patients feels different to what he was formerly in the body-ego, the psychic-ego and in his relation to the outer world. The terminology of Wernicke seems satisfactory: somatopsychic, autopsychic and alopsychic depersonalization (strangeness of the world or disrealization of Mapother-Mayer-Gross).

3 - Depersonalization can reach partial aspects or the total body and psychic-ego; alienation or strangeness of this or that organ or part of the body or the whole body; the emotions, ideas, or volitions as the totality of the psyche. In extreme cases there arises the picture of the delusion of negation or phenomena of "double conscience" or multiple personality.

4 - Approaching the cases of depersonalization with some neurological ones (hallucination of amputed limbs, anosognosia, autoscopia) brings certain explanations as to its neuro-pathogenic mechanisms. But here it is question, as Krapf shows, of instrumental phenomena farther away from the ego than authentic depersonalization (Krapf refers to the cases of disrealization with hemianopsia or hemianosognosia studied by Ehrenwald, von Stöckrt and Krapf). Besides this, the mere considerations of neuro-anatomopathological mechanisms (in the case still obscures) would not be able to explain the psychodynamic of the depersonalization. 
5 - In our cases the clinical examination (with many complementary proofs) was negative as to the existence of organic affection (in a strict sense) of the nervous system. In all of our patients (with much more evidence in the four first ones) we feel it is a question of "sickness of the personality" or, more precisely, "sickness of the ego". Very intense endopsychic conflicts arise and - not being dissolved - impel the ego to the split. The satisfactory solution of such conflicts was followed by a cure in the first four cases. As was reported, eleven patients of our series had not responded to biological therapeutic (electrochocktherapy) or to psychosurgical methods (frontal lobotomy). It was a question of depersonalization associated with grave psychosis in which our intention was above all to investigate problems of psychopathology and not so much of therapy.

6 - We found the following mechanisms at the base of the depersonalization: a) conflict between hetero and homosexual tendencies interfering intensely in the character and behavior (first case) in which the necessity to reaffirm the own sex in situations strongly suggestive of contrary tendencies, provoked depersonalization (mechanism described by Oberndorf); b) intense conflict in the sense of rejection of the physical ego (feelings of inferiority) was observed in case (case 2) of a patient who forced herself to deny her body but immediately there arose emotional conflicts with the mother. The hetero and homosexual conflicts had connections with the identification with the father and the rejection of the feminine rôle. When she affirmed her own sex (feminine) by rejection of masculinity, arose depersonalization; c) in both cases the deepening of the analysis demonstrated, however, that the essential was more profoundly rooted. Indeed, an intense conflict arose between tendencies of strong dependence on the mother and many situations of rejection by her. There was a very deep situation of basic anxiety related to the fear of self-destruction by complete abandon (death). Such a mechanism arose with particular evidence in case 3 in which the patient rationalized the motives of hate but essentially mobilized the superficial aggression in order not to be invaded by the anxiety of death on account of the abandonment which she suffered in infancy. All this emotional constellation fell on the ego in the form of reversal of aggression in a degree so intense that the only adequate defence was the split (masochistic mechanism).

7 - In many cases the split is not sufficient, even when processed at the most archaic levels by the effect of regression. Then, arise the "restitution mechanisms" (Freud) or "progression mechanisms" (Glover) as hallucinations, delusions, automatic phenomena of influence (transitivism), presenting the picture of depersonalization within the psychosis. This means greater weakness of the ego or greater intensity of conflicts.

8 - In many cases we note the close relationship of depersonalization with hypochondria, considered as an increase in the investment of organs in detriment to that of objects. The repression by the countercathexis of the displeasing sensations can lead to feelings of alienation or strangeness, 
as shown by Tausk, Fenichel and others. However, also in these cases a deeper investigation always reveal the aggression impulses against immediate objects (considered as primaries objects) turned back against the ego. If hypochondria is a phenomenon of an increase of the narcisistic investment of the organ, the aggression component in organs symbolizing objects is also at times very evident.

9 - In neurotic depersonalization psychotherapy analytically oriented (exhuming the conflicts and solving them) or preferably psychoanalytic treatment is indicated. When depersonalization is part of the symptomatology of a psychosis, it accompanies the general indications of modern biologic techniques of shock and the modern methods of psychotherapy.

\section{REFERENCIAS}

1. ABRAHAM, K. - a) The psycho-sexual differences between hysteria and dementia praecox (1908); b) A short study of the development of the libido, viewed in the light of mental disorders (1924). In "Selected Papers" compilados por D. Bryan e A. Strachey. Hogarth Press, Londres, 1927. 2. AJURIAGUERRA, J.; HECAEN, H. - a) Troubles de la somatognosie et états de transformation locale des fonctions nerveuses. In $\mathrm{H}$. Ey, J. de Ajuriaguerra et $\mathrm{H}$. Hécaen - Les rapports de la Neurologia et de la Psychiatrie. Herman éd., Parjs, 1947. 3. BLEULER, E. - a) Dementia praecox or the group of schizophrenias. Intern. Univ. Press, Nova York, 1952; b) Lehrbuch der Psychiatrie, 8ः edição, Springer Verlag, Berlin-Göttingen-Heildelberg, 1949, págs. 77-80 e 276-321. 4. BERGLER, E. - a) Further studies on depersonalization. Psychiat. Quarterly, 24:268, 1950; b) The Basic Neurosis. Oral Regression and Psychic Masochism. Grune Stratton, Nova York, 1949. 5. BERGLER, E.; EIDELBERG, L. - Der Mechanismus der Depersonalisation. Internat. Zeitschr. f. Psychoanal., 21:258, 1935 6. BERMAN, L. - Depersonalization and the body ego with special reference to the genital representation. Psychoanal. Quarterly, 18:433, 1948, 7. BICHOWSKI, G. - Disorders in the body image in the clinical pictures of psychosis. J. Nerv. a. Ment. Disease, 97:310, 1943. 8. BOCKNER, S. - The depersonalization syndrome: report of a case. J. Ment. Science, 95: 401, 1949. 9. BOGAERT, L. van - Sur la pathologie de l'image de soi. Ann. Méd. Psychol., 92:519 e 744, 1934. 10. BLANK, H. R. J. - Depression, hypomania and depersonalization. Psychoanal. Quartely, 23:20, 1954. 11. BRUSH, N. B. - The psychasthenic reaction. Amer. J. Psychiat., 8, 1938. 12. CALLIERI, B.; SEMERARI, A. - Contributo psicopatologico e critico al concetto di depersonalizzazione (con particulare riguardo alla forma autopsichica). Rass. Studi Psichiat., 42, 1953.13. CAMBRIELS - Psycho-névrose obsédante de dépersonnalisation avec “moyens de léfense" anti-dépersonalisateurs. Encéphale, 36:330, 1931. 14. CARP, E. - Troubles de l'image du corps. Acta Neurol. et Psychiat. Bélgica, 52:461, 1952.15. CLAUDE, H. - Définition et nature de l'hystérie. Congrès des Alienistes et Neurologistes, Genève-Lausanne, agôsto, 1907. 16. DENY, G.; CAMUS, P. - a) Sur un cas de délire métabolique de la personnalité lié à des troubles de la cénesthesie. Arch. de Neurol. (Paris), 20:257, 1905; b) Sur une forme d'hypochondrie aberrante due à la perte de la conscience du corps. Rev. Neurol., 9:461, 1905. 17. DUGAS, L. - a) Un cas de dépersonnalisation. Rev. Philos, 1:503, 1888; b) Sur la dépersonnalisation. J. Psychol. Norm. et Pathol., 33:276, 1936; c) Dépersonnalisation et absence. J. de Psychol., 33:359, 1936. 18. DUGAS, L.; MOUTIER, F. - La dépersonnalisation et la perception exterieure. J. de Psychol. Norm. et Pathol., 7: 481, 1910. 19. DUPRE, E; CAMUS, P. - Les cénesthopathies. Encéphale, 2, 1907. 20. EIDELBERG, L. - An outline of a comparative pathology of the neuroses. Internat. Univ. Press, Nova York, 1954, pág. 152. 21. EY, H. - Etudes Psychia- 
triques. Desclée de Brouver et Cie., Paris, 1948, 1950, 1954 ( 3 vols.). 22. EY, H.; ROUART, J. - Essai d'Application des Principes de Jackson à une Conception Dynamique de la Neuropsychiatrie. Gaston Doin et Cie., Paris, 1938. 23. FAIRBAIRN, W. R. D. - - a) A revised psychopathology of the psychoses and psychoneuroses. Internat. J. Psycho-Analysis, 22:250, 1941; b) Psychoanalytic Studies of the Personality. Tavistock Publ. Ltd., Londres, 1952, 24. FEDERN, P. - $a$ ) Das Ich als Subjekt und Objekt in Narzisismus. Internat. Zeitschr. f. Psychoanal., 15:393, 1929; b) Ego Psychology and the Psychoses. Basic Book Publishers Inc., Nova York, 1952. 25. FEIGENBAUM, D. - Depersonalization as a defence mechanism. Psychoanal. Quarterly, 6, 1937. 26. FENICHEL, O. - a) uber Organlibidinöse Begleiterscheinungen der Triebabwehr. Internat. Zeitschr. f. Psychoanal., 14:45, 1928; b) The Psychoanalytic Theory of Neurosis. Norton Co., Inc., Nova York, 1945. 27. FERENCZI, S. - a) Sex in Psychoanalysis. R. Brunner, Nova York, 1950; b) Confusion of tongues between the adult and the child. Internat. J. Psycho-Analysis, 30:225, 1949. 28. FOLLIN, S. - Le processus de dépersonnalisation. Premier Congrès Mondial de Psychiatrie, Paris, 1950. 29. FREUD, S. - a) Eine Erinnerungsstörung auf der Akropolis. Internat. Psychoanal, Verlag, Viena, 1937; b) Splitting of the ego in the defensive process. Internat. J. Psycho-Analysis, 22:65, 1941; c) An outline of psycho-analysis. Internat. J. Psycho-Analysis, 21:27, 1940. 30. GERSTMANN, J. Problems of imperception of disease and of impaired body territories with organic lesions. Relation to body scheme and its disorders. Arch. Neurol. a. Psychiat., 48: 890, 1942. 31. GRUHLE, H. W. - Verstehende Psychologie. Thieme Verlag, Stuttgart (2. Auflage), sem data). 32. GUTTMANN, E.; MACLAY, W. S. - Mescaline and depersonalization. J. Neurol. a. Psychopathol., 16:193, 1936. 33. HARTMANN, H. - Ein Fall von Depersonalisation. Zeitschr, f. d. ges. Neurol. u. Psychiat., 74: 593, 1922. 34. HAUG, K. - a) Die Störungen des Persönlichkeitsbewusstseins und verwandte Entfremdungserlebnisse. F. Enke, Stuttgart, 1936; b) Depersonalisation und verwandte Erscheinungen. In $\mathrm{O}$. Bumke-Handbuch der Geisteskrankheiten. Bd. 1. Springer Verlag, Berlim, 1939. 35. HEIMAN, P. - Certain functions of introjection and projection in early infancy. In M. Klein, P. Heiman, S. Isaacs e J, Riviere - Developments in Psycho-Analysis. Hozarth Press, Londres, 1952.36. HEAD, H.; HOLMES, G. - Sensory disturbances from cerebral lesions. Brain, 34: 102, 1911. 37. HẼCAEN, H.; AJURIAGUERRA, J. - Méconnaissances et hallucinations corporelles. Integration et desintegration de la somatognosie. Masson et Cie., Paris, 1952. 38. HERNARD, A. - a) La signification psychanalitique des sentiments dits de dépersonnalisation. Rev. Franc. de Psychanalyse, 1:87, 1927; b) Nouvelle contribution psychanalitique à l'étude des sentiments dits de dépersonnalisation. Rev. Franc. de Psychanalyse, 7:272, 1934. 39. HEUYER, G.; SÉRIN, S. Syndrôme de dépersonnalisation consecutif à une encéphalite épidemique. Encéphale, 25:629, 1930. 40. HEUYER, G.; DUBLINEAU, J. - Syndrôme de dépersonnalisation chez un encéphalitique. Ann. Méd. Psychol., 1, 1932. 41. JAMES, W. - Précis de Psychologie. Marcel Rivière, Paris, 1929. 42. JANET, P. - Les Obsessions et la Psychasthénie, $3^{\text {n }}$ ed. Félix Alcan, Paris, 1919. 43. KLEIN, M. - a) The PsychoAnalysis of Children. Hogarth Press, Londres, 1937; b) Notes on some schizoid mechanisms. Internat. J. Psycho-Analysis, 27:99, 1946. 44. KRAEPELIN, E. - Psychiatrie. III B. J. Ambrosius Barth, Leipzig, 1923, pág. 1259. 45. KRAPF, E. - $a$ ) La despersonalización desde el punto de la psicopatología general. Rev. de la Univ. de Buenos Aires, 2, 1, 1944; b) Sur la dépersonnalisation. Premier Congrès Mondial de Psychiatrie, Paris, 1950. 46. LAIGNEL-LAVASTINE, M.; BRISSET, Ch.; FOLLIN, S. - Sentiment de dépersonnalisation chez une mélancolique anxieuse. Ann. Méd. Psychol., 98:144, 1940. 47. LHERMITTE, J. - De l'image corporelle. Rev. Neurol., 74:20, 1942. 48. LHERMIT'TE, J.; TCHEHERAZI, E. - L'image du moi corporelle et ses déformations pathologiques. Encéphale, 1, 1937. 49. MAYERGROSS, W. - Selbstschilderungen der Verwirrtheit. Die oniroide Erlebnisform. Springer Verlag, Berlim, 1924. 50. MORSELLI, G. E. - Il problema della Spersonalizzazione. Sist. Nervoso, $3: 243$, 1951. 51. NUNBERG, H. - Uber Depersonalisationszustände im Licht der Libidotheorie. Internat. Zeitschr. f. Psychoanal., 10:17, 1924. 52. OBERNDORF, C. P. - a) Depersonalization in relation to erotization of 
thought. Internat. J. Psycho-Analysis, 15:271, 1934; $b$ ) The genesis of the feeling of unreality. Internat. J. Psycho-Analysis, 16:296, 1935; c) on retaining the sense of reality in states of depersonalization. Internat. J. Psycho-Analysis, 20:137, 1939; d) The role of anxiety in depersonalization. Internat. J. Psycho-Analysis, 31:1, 1950. 53. PETO, A. - On so-called depersonalization. Internat. J. Psycho-Analysis, 36:379, 1955. 54. REIK, Th. - Psicología y despersonalización. Rev. de Psicoanálisis (Buenos Aires), 2:443, 1945. 55. RIBOT, Th. - Problème de Psychologie Affective: la Conscience Affective. Monografia sem data de publicação (pág. 26, nota 1). 56. ROSENFELD, H. - Analysis of a schizophrenic state with depersonalization. Internat. J. Psycho-Analysis, 28:130, 1947. 57. SADGER, I. - Uber Depersonalisation. Intern. Zeitschr. f. Psychoanalyse, 14:315, 1928. 58. SHORVON, H. J. - Psychopathologie de la dépersonnalisation. Premier Congrès Mondial de Psychiatrie, Paris, 1950. 50. SHORVON, H. J.; SARGANT, W. - Excitatory abreaction: with special reference to its mechanism and the use of ether. J. Mental Science, 93:709, 1947. 60. SCHILDER, P. - $-a$ ) Selbstbewusstsein und Persönlichkeitsbewusstsein (Eine psychopathologische Studie). Springer Verlag, Berlim, 1914; b) Die Depersonalisation. In Medizinische Psychologie. Springer Verlag, 1924, págs. 257261; c) The Image and Appearance of the Human Body. Psyche Monographs, Tr. Trubner Co., Nova York, 1935; d) Goals and Desires of Man. Columbia Univ. Press, Nova York, 1942, págs. 188-197. 61. SToRRING, E. - Die Depersonalisation. Eine psychopathologische Untersuchung. Arch. f. Psychiat. u. Nervenkrankheit, 98: 462, 1953. 62. TAUSK, V. - On the origin of the influencing machine in Schizophrenia. Psychoanal. Quarterly, 2:542, 1933. 63. UCHÓ, D. M. - a) Estrutura psicológica da neurose compulsiva. Arq. da Assist. a Psicop. São Paulo, 10-11:125, 1947; b) Psiquiatria e Psicanálise. Livraria Vademecum Ed., São Paulo, 1952. 64. WITTELS, F. - Psychology and treatment of depersonalization. Psychoanal. Rev., 27:57, 1940. 65. WAMBERTO DE MORAIS -- Fenomenologia e semiologia dos sintomas de despersonalização. Neurobiologia (Recife), 11:126, 1946. 66. WINNICOTT, D. W. - Primitive emotional development. Internat. J. Psycho-Analysis, 26:137, 1945.

Rua Bráulio Gomee, 25, 7o andar - Sāo Paulo, Brasil. 